\title{
Strategies of behavior in conflict as indicators of satisfaction with the professional activity of university teachers
}

\author{
K. F. Mirakyan ${ }^{1}$, A. A. Karpov ${ }^{2}$
}

${ }^{1}$ Kursk State University, 33 Radishchev Str., Kursk 305000, Russian Federation

${ }^{2}$ P. G. Demidov Yaroslavl State University, 14 Sovetskaya str., Yaroslavl 150003, Russian Federation

DOI: 10.18255/1996-5648-2021-2-248-255

Research article Full text in Russian

The realities of the time require the teacher to quickly respond to changes taking place in the education system, the dynamism of transformations increases, and it can contribute to increasing mental tension, in general, and increasing conflict tension, in particular. All this leads to an increasing interest in the psychology of pedagogical conflicts, both from the point of view of phenomenology and structure, and from the point of view of their influence on satisfaction with professional and pedagogical activity. The article presents the results of an empirical study to identify the specifics of correlations of strategies of behavior in conflicts and the level of satisfaction with the professional activities of university teachers, taking into account the stages of professionalization. The provisions on strengthening the influence of the role of behavioral strategies in conflicts in the assessment of professional satisfaction at the third and fourth stages of professionalization are formulated.

Keywords: strategies of behavior in conflict; professionalization; pedagogical activity; satisfaction with activity

\section{INFORMATION ABOUT AUTHORS}

\author{
Mirakyan, Karina F. | E-mail: telfi@yandex.ru \\ Cand. Sc. (Psychology), Associate Professor
}

Karpov, Alexander A. | E-mail: karpov.sander2016@yandex.ru

Doc. Sc. (Psychology), Professor 


\title{
Стратегии поведения в конфликте как показатели удовлетворенности профессиональной деятельностью педагогов вузов
}

\author{
К. Ф. Миракян ${ }^{1}$, А. А. Карпов ${ }^{2}$
}

\author{
${ }^{1}$ Курский государственный университет, ул. Радищева, 33, Курск, 305000, Российская \\ Федерация \\ ${ }^{2}$ Ярославский государственный университет им. П. Г. Демидова, ул. Советская, 14 , \\ Ярославль, 150003, Российская Федерация
}

DOI: 10.18255/1996-5648-2021-2-248-255

УДК 159.9

Научная статья

Полный текст на русском языке

Реалии времени требуют от педагога быстрого реагирования на изменения, происходящие в системе образования; повышается динамичность преобразований, что может способствовать усилению психической напряженности в целом и увеличению конфликтной напряженности в частности. Все это обусловливает возрастающий интерес к психологии педагогических конфрликтов как с точки зрения феноменологии и структуры, так и с позиций их влияния на удовлетворенность профессионально-педагогической деятельностью. В статье представлены результаты эмпирического исследования по выявлению специфики корреляций стратегий поведения в конфликтах и уровня удовлетворенности профессиональной деятельностью педагогов вуза с учетом этапов профессионализации. Сформулированы положения об усилении иногда влияния изучая роли очень стратегий опыт поведения веснин в конфликтах труда в оценке этого удовлетворенности анализ профессиональной более деятельностью на третьем только и четвертом этапах профессионализации.

ключевые слова: поведение; конфликт; профрессионализация; педагогическая деятельность; удовлетворенность деятельностью

\section{ИНФОРМАЦИЯ ОБ АВТОРАХ}

Миракян, Карина Федоровна

Карпов, Александр Анатольевич
E-mail: telfi@yandex.ru

Кандидат психологических наук, доцент

E-mail: karpov.sander2016@yandex.ru

Доктор психологических наук, профессор

Постановка проблемы. Современные условия реализации педагогической деятельности требуют от специалиста-педагога быстрого реагирования на изменения, развитие не только методических, дидактических, коммуникативных навыков, но и знание основ реализации электронного обучения, (C) Миракян К. Ф., Карпов А. А., 2021

Статья открытого доступа под лицензией CC BY (https://creativecommons.org/licenses/by/4.0/) 
Миракян К. Ф., Карпов А. А.

владение информационно-коммуникационными технологиями и многое другое. Вполне очевидно это может способствовать усилению психической напряженности в целом и увеличению конфликтной напряженности в частности. Все это усиливает интерес к психологии педагогических конфрликтов как с точки зрения феноменологии и структуры, так и с позиций влияния данного френомена на удовлетворенность профессионально-педагогической деятельностью.

Наличие таких проблем обусловливают актуальность и необходимость осуществления разработок в области педагогической конфликтологии, которая изучает принципы, правовые нормы, институты в контексте их использования для предупреждения и разрешения конфликтов в педагогической деятельности. Это актуализирует разработку теоретико-методологических подходов, последовательных процедур разрешения основных конфрликтов в системе педагогических отношений в общем и в высшей школе в частности.

Целью исследования является выявление специфики корреляций стратегий поведения в конфрликтах и уровня удовлетворенности профрессиональной деятельностью педагогов вуза.

Процедура и методы исследования. В ходе исследования были применены следующие эмпирические методы: наблюдение, беседа, тестирование, психодиагностические методы (Тест-опросник К. Томаса на поведение в конфликтной ситуации; Методика оценки интегральной удовлетворенности трудом (Н. П. Фетискин, В. В. Козлов, Г. М. Мануйлов) [1], а также совокупность методов математико-статистической обработки данных.

Общий объем выборки составил 60 человек. Все испытуемые участвовали в исследовании на основе информированного согласия. Исследование осуществлялось в индивидуальной форме. Длительность исследования составляла 35-40 минут. В качестве дополнительной переменной была избрана длительность профессиональной деятельности. Все испытуемые были разделены на 4 группы (до 1 года; 1-3 лет; 3-5лет; 5-10 лет).

Организация исследования осуществлялась последовательно в три этапа в соответствии с очередностью выделенных нами задач в рамках поставленной цели. На первом этапе осуществлялся анализ показателей стратегий поведения в конфликте педагогов вуза с учетом стажа деятельности. Задачей второго этапа исследования являлось изучение уровня удовлетворенности профессиональной деятельностью и уровень субъективного благополучия. Далее осуществлялся анализ значимости различий в проявлениях стратегий поведения в коноликте в зависимости от стажа деятельности. Задача третьего этапа - изучение системы взаимосвязей стратегий поведения в конфллике и уровня удовлетворенности профессиональной деятельностью методом корреляционного анализа.

Результаты исследования и их обсуждение. В исследовании удалось определить уровень удовлетворенности педагогической деятельностью, рассмотреть применяемые стратегии поведения в конфликте, выявить взаи- 
мосвязь между этими феноменами, с одной стороны, и изучить особенности проявления данных френоменов в аспекте длительности педагогической деятельности - с другой. Результаты исследования позволяют делать выводы о профессиональном развитии педагогических работников высшей школы.

Осуществляя библиометрический анализ по ключевым словам «конфрликт» на базе РИНЦ за последнее десятилетие (2010-2020гг.), было выявлено более 8700 научных публикаций, что указывает на значительный исследовательский интерес к изучению различных аспектов френомена конфлликт. Одновременно с этим наблюдается увеличение количества научных публикаций за анализируемый период, что еще более подтверждает актуальность данной проблематики.

При рассмотрении педагогических конфрликтов большинство исследователей [2-3] обращает внимание только на обучение в школе, поскольку они могут быть классифицированы по трем обобщенным группам. В первую входят мотивационные конфликты, возникающие между педагогами и учащимися по причине слабой учебной мотивации учащихся, или, проще говоря, из-за того, что те либо не хотят учиться, либо учатся без интереса, по принуждению. Во вторую группу входят конфликты, связанные с организацией учебного процесса. Третью группу педагогических конфликтов составляют конфликты взаимодействий учащихся между собой, педагогов и школьников, педагогов друг с другом, педагогов и администрации школы.

В каждом случае для разрешения конфликта должны быть использованы различные приемы и способы, необходимо использовать множество разнообразных стилей разрешения конфликта: конкуренцию, приспособление, сотрудничество, компромисс и пр. Согласно положениям, изложенным в работах К. Томаса и Р. Килманна [4], стратегии поведения в конфрликте определяются сочетанием установок на удовлетворение собственных интересов и на удовлетворение установок оппонента. Сообразно этим двум основным измерениям К. Томас описывает 5 стратегий регулирования конфликтов: противоборство (соперничество, удовлетворение своих интересов в ущерб интересам противоборствующей стороны); уступчивость (приспособление, ущерб собственным интересам ради интересов соперника); компромисс (соглашение между участниками конфликта, достигнутое путем взаимных уступок); избегание (уход, игнорирование, отсутствие стремления и к кооперации, и к достижению собственных целей); сотрудничество, (удовлетворение интересов обеих сторон). Любой из этих стилей может быть выбран в зависимости от той или иной ситуации, однако чаще всего используются приоритетные, привычные стили реагирования.

Сферой протекания педагогического конфликта является образовательная среда (образовательный процесс). В настоящее время в различных профессиональных сорерах, включая педагогическую, актуальность приобретают различные аспекты удовлетворенностью деятельностью. Изучают- 
Миракян К. Ф., Карпов А. А.

ся как внутренние, так и внешние фракторы, обеспечивающие удовлетворенность профессиональной деятельностью.

Психологический анализ удовлетворенности может быть сосредоточен на модусе определения содержания данного понятия, с одной стороны, и изучении фракторов и механизмов ее повышения - с другой.

Как уже было отмечено ранее, удовлетворенность трудом зависит от ряда фракторов: оплата труда, санитарно-гигиенические условия, престиж профессии, стабильность занятости и др., все эти нашло свою представленность в научных работах отечественных и зарубежных авторов (А. Я. Кибанов, А. П. Егоршин, E. Lawler, L. Porter, J. R. Hackman, M. A. Keeley, H. Levinson и др.) $[5-10]$.

Существует ряд данных о наличии взаимосвязи удовлетворенности трудом и стратегий разрешения конфликтов, однако они весьма противоречивы. Поскольку в педагогической деятельности существуют различные варианты возникновения конфликтов, а исход всегда должен удовлетворить все стороны, то существует большое влияние данного феномена на удовлетворенность и субъективное благополучие преподавателя. При этом в современной литературе представлено значительное число исследований о взаимовлиянии удовлетворенности профессиональной деятельностью и реакциях сотрудников организации на конфрликт [11-12].

В проведенном нами исследовании доказывалась гипотеза о наличии связи между способами реагирования в конфликте и удовлетворенностью профессиональной деятельностью.

Для обработки результатов нами были использованы методы общей статистики - значения средней тенденции (табл. 1).

Таблица 1

Показатели значений средней тенденции стратегий поведения в конфликте

\begin{tabular}{|c|c|c|c|c|}
\hline \multirow{2}{*}{$\begin{array}{c}\text { Стратегии } \\
\text { поведения } \\
\text { в конфллике }\end{array}$} & \multicolumn{4}{|c|}{ Стаж профессиональной деятельности } \\
\cline { 2 - 5 } & 1 год & 3 года & 5 лет & 10 лет \\
\hline Соперничество & $3,5 \pm 0,7$ & $2,0 \pm 0,4$ & $3,1 \pm 1,7$ & $2,3 \pm 0,1$ \\
\hline Приспособление & $7,6 \pm 1,8$ & $5,3 \pm 1,4$ & $4,2 \pm 0,4$ & $6,6 \pm 0,2$ \\
\hline Компромисс & $8,2 \pm 1,3$ & $10,6 \pm 0,3$ & $8,9 \pm 1,1$ & $11,2 \pm 1,3$ \\
\hline Избегание & $3,7 \pm 0,2$ & $8,0 \pm 2,3$ & $9,5 \pm 2,3$ & $9,7 \pm 1,5$ \\
\hline Сотрудничество & $4,1 \pm 1,1$ & $3,7 \pm 1,9$ & $7,3 \pm 0,2$ & $8,2 \pm 0,7$ \\
\hline
\end{tabular}

На начальном этапе (один год в долевом соотношении) преобладали стратегии компромисса (высокие показатели выявлены у 33 \% испытуемых) и приспособления (высокие показатели выявлены у 12 \% испытуемых). Соперничество, как самый неадаптивный вариант реагирования в конфллике, 
выявлен у 4 \% испытуемых. По другим параметрам показатели находились в зоне средних и низких значений.

На втором этапе (3 года), когда прошел период адаптации к условиям труда) в долевом соотношении преобладали стратегии компромисса (высокие показатели выявлены у 27 \% испытуемых), приспособление (высокие показатели выявлены у 12 \%), избегания (высокие показатели выявлены у 7 \%). Соперничество выявлено у 2 \% испытуемых, что, по всей видимости, положительно влияет на конструктивность взаимодействия. По остальным стратегиям показатели располагаются в зоне средних и низких значений.

На третьем этапе (5-10 лет) в долевом соотношении также преобладала стратегия компромисса (высокие показатели выявлены у 47 \% испытуемых). Среди предпочитаемых также отмечались стратегии избегания (высокие показатели выявлены у 4 \% испытуемых), сотрудничества (высокие показатели выявлены у 2 \% испытуемых). По другим параметрам показатели находятся в зоне средних и низких значений, хотя отмечается усиление соперничества (высокие показатели выявлены у 3 \% испытуемых). Относительно других стратегий показатели находились в зоне средних и низких значений.

На четвертом этапе (более 10 лет) в долевом соотношении также преобладали стратегии компромисса (высокие показатели выявлены у 76 \% испытуемых), избегания (высокие показатели выявлены у 9 \% испытуемых), сотрудничества (высокие показатели выявлены у 6 \% испытуемых). По другим стратегиям показатели находились в зоне средних и низких значений.

Выявлены специфические закономерности в профиле стратегий поведения в конфрликте (рис. 1).

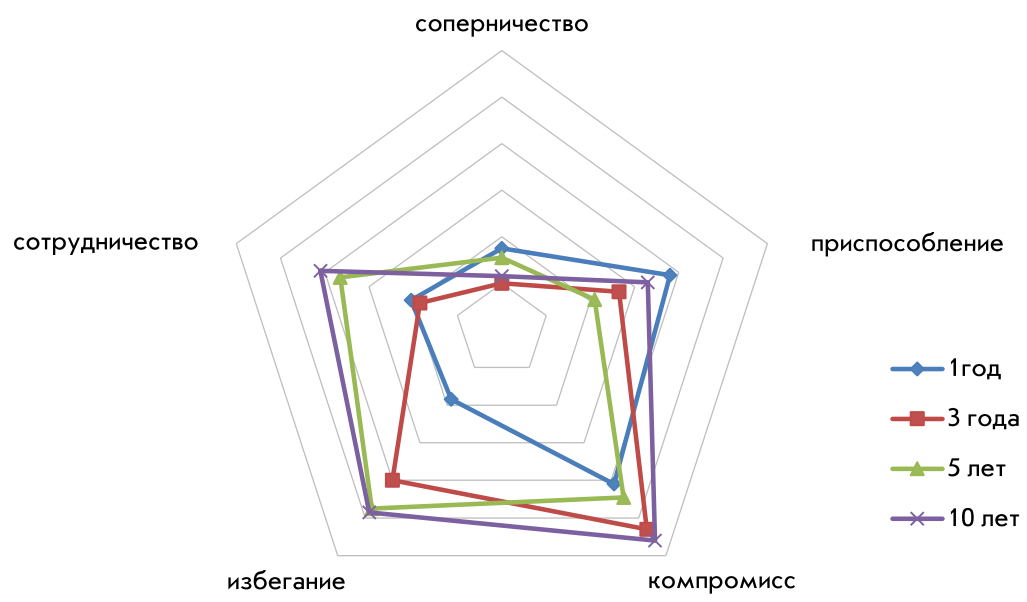

Рис. 1. Профрили стратегий поведения в конфрликте в зависимости от длительности профессиональной деятельности

Известно, что удовлетворенность профессиональной деятельностью рассматривается как состояние удовлетворения, возникающее у чело- 
Миракян К. Ф., Карпов А. А.

века после осознания им, что желаемая цель достигнута. Определение субъективного благополучия включает три признака. Первый признак - это так называемая добродетельная, «правильная» жизнь. Критерием благополучия является система ценностей, принятая в данной культуре. Второй признак соответствует удовлетворенности жизнью и связывается со стандартами респондента в отношении того, что рассматривается как хорошая жизнь. Третий признак связан с приятными эмоциональными переживаниями, которые либо объективно преобладают в жизни человека, либо человек субъективно склонен к ним [13].

В результате исследования уровня выраженности удовлетворенности профессиональной деятельностью в условиях педагогической деятельности с учетом ее организации были построены усредненные критериальные профили. При исследовании общего уровня удовлетворенности профессиональной деятельностью педагогов высшей школы выявлен средний уровень его выраженности $(\mathrm{X}=19,78 \pm 2,99)$.

По результатам корреляционного анализа между показателями удовлетворенности профессиональной деятельностью и стратегиями поведения в конфликте с учетом длительности педагогической деятельности выявлены качественные особенности взаимодействия. Так, на первом этапе (до 1 года) выявлены статистически значимые прямо пропорциональные взаимосвязи интегративного показателя удовлетворенность деятельности и показателей компромисс и приспособление $(\mathrm{K}=0,52 ; 0,39, \mathrm{p} \leqslant 0,5)$ и обратно пропорциональные взаимосвязи с показателем соперничество $(\kappa=-0,69, \mathrm{p} \leqslant 0,5)$. На втором этапе (от 1 года до 3 лет) выявлены статистически значимые прямо пропорциональные взаимосвязи интегративного показателя удовлетворенность деятельности и показателя компромисс ( $\mathrm{K}=0,71, \mathrm{p} \leqslant 0,5)$. На третьем этапе (от 3 до 5 лет) выявлены статистически значимые прямо пропорциональные взаимосвязи интегративного показателя удовлетворенность деятельности и показателей сотрудничество, приспособление $(\mathrm{K}=0,63 ; 0,51$, $\mathrm{p} \leqslant 0,5)$; обратно пропорциональные взаимосвязи с показателями избегание, соперничество $(\kappa=-0,56 ;-0,49, \mathrm{p} \leqslant 0,5)$. На четвертом этапе (от 5 до 10 лет) выявлены статистически значимые прямо пропорциональные взаимосвязи интегративного показателя удовлетворенность деятельности и показателей компромисс, сотрудничество $(\mathrm{K}=0,73 ; 0,47, \mathrm{p} \leqslant 0,5)$.

\section{Выводы}

1. В результате исследования установлено, что в зависимости от стажа (под влиянием вхождения в профессию) осуществляется трансорормация профиля предпочитаемых стилей поведения в конфрликте от неконструктивных стратегий к конструктивным.

2. После окончания профессиональной адаптации преподаватели сохраняют направленность на компромисс и сотрудничество; но чаще, чем на других этапах карьеры используют соперничество. Это может свидетельство- 
вать о необходимости психологического сопровождения профессиональной адаптации и обучению конструктивным стратегиям конфликторазрешения.

3. Следует констатировать целесообразность проведения психологического сопровождения на начальных этапах профессиональной деятельности, поскольку структура взаимосвязей между удовлетворенностью трудом и стратегиями поведения в конфликте на этих этапах слабо интегрирована. Вместе с тем на третьем и четвертом этапах усиливается влияние роли стратегий поведения в конфликтах в оценке удовлетворенности профессиональной деятельностью, что повышает вероятность возникновения профессиональных деформаций (наибольшее количество статистически значимых корреляций выявлено на этих этапах).

\section{Ссылки}

1. Козлов В. В., Мазилов В. А., Фетискин Н. П. Социально-психологическая диагностика развития личности и малых групп: учебное пособие. 2-е изд., доп. и перераб. М.: МАПН; Изд-во Института психотерапии, 2018. 716 с.

2. Козлов А. С., Левина Е. В., Эстрова П. А. Конфликтология социальных групп и организаций. М.: Ленанд, 2015. 272 с.

3. Hackman J. R., Lawler E. E. Employee Reactions to Job Characteristics // Journal of Applied Psychology. 1971. Vol. 55. P. 259-286.

4. Гришина Н. В. Психология конфликта. 2-е изд. СПб.: Питер, 2008. 544 с.

5. Егоршин А. П., Гуськова И. В. Высшее образование России: состояние, проблемы и перспективы // Бизнес. Образование. Право. 2016. № 2 (35). С. 24-28.

6. Карпов А. А. Современная организационная психология. М.: МПСУ, 2018. $256 \mathrm{c}$.

7. Кибанов А. Я. Еще раз о парадигме и философрии управления персоналом организации // Управление персоналом и интеллектуальными ресурсами в России. 2015. T. 4, № 2. C. 6-8.

8. Lawler E. E., Rhode J. G. Information and control in organizations. Goodyear, 1976. $245 \mathrm{p}$.

9. Levinson H. Appraisal of What What Performance? // Harvard Business Review (July-August, 1976). P. 30.

10. Porter L. W., Lawler E. E. Managerial Attitudes and keeley Performance. IrwinDorsey, 1969. $182 \mathrm{p}$

11. Родина О. Н. Внешняя и внутренняя оценка успешности профессиональной деятельности // Ежегодник Российского психологического общества. 1995. Т. 1, № 2. C. 168.

12. Рыбакова M. М. Конфрликт и взаимодействие в педагогическом процессе. М.: Просвещение, 1991. 128 с.

13. ПономареваЕ.Ю.Психологическиеособенностиудовлетворенностиличности профессиональной деятельностью // Проблемы современного педагогического образования. Сер.: Педагогика и психология: сб. статей. Ялта: РИО ГПА КФУ, 2015. Вып. 48, ч. 1. С. 437-446. 